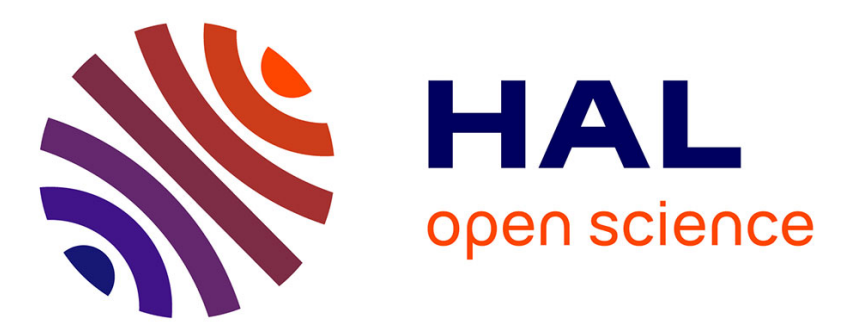

\title{
Kisspeptin Signaling in the Brain: Recent Developments and Future Challenges
}

Manuel Tena-Sempere

\section{To cite this version:}

Manuel Tena-Sempere. Kisspeptin Signaling in the Brain: Recent Developments and Future Challenges. Molecular and Cellular Endocrinology, 2009, 314 (2), pp.164. 10.1016/j.mce.2009.05.004 . hal-00547651

\section{HAL Id: hal-00547651 \\ https://hal.science/hal-00547651}

Submitted on 17 Dec 2010

HAL is a multi-disciplinary open access archive for the deposit and dissemination of scientific research documents, whether they are published or not. The documents may come from teaching and research institutions in France or abroad, or from public or private research centers.
L'archive ouverte pluridisciplinaire HAL, est destinée au dépôt et à la diffusion de documents scientifiques de niveau recherche, publiés ou non, émanant des établissements d'enseignement et de recherche français ou étrangers, des laboratoires publics ou privés. 


\section{Accepted Manuscript}

Title: Kisspeptin Signaling in the Brain: Recent Developments and Future Challenges

Author: Manuel Tena-Sempere

PII: $\quad$ S0303-7207(09)00270-6

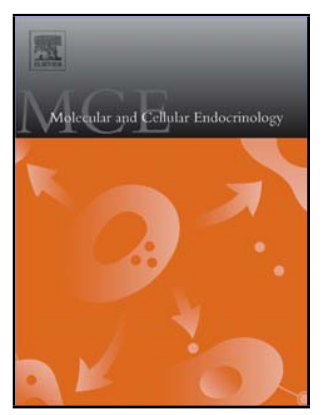

DOI: $\quad$ doi:10.1016/j.mce.2009.05.004

Reference: $\quad$ MCE 7217

To appear in: $\quad$ Molecular and Cellular Endocrinology

Received date: $\quad 22-2-2009$

Accepted date: $\quad$ 13-5-2009

Please cite this article as: Tena-Sempere, M., Kisspeptin Signaling in the Brain: Recent Developments and Future Challenges, Molecular and Cellular Endocrinology (2008), doi:10.1016/j.mce.2009.05.004

This is a PDF file of an unedited manuscript that has been accepted for publication. As a service to our customers we are providing this early version of the manuscript. The manuscript will undergo copyediting, typesetting, and review of the resulting proof before it is published in its final form. Please note that during the production process errors may be discovered which could affect the content, and all legal disclaimers that apply to the journal pertain. 


\section{Kisspeptin Signaling in the Brain: Recent Developments and Future Challenges}

Manuel Tena-Sempere

Department of Cell Biology, Physiology and Immunology, University of Córdoba; and CIBER Fisiopatología de la Obesidad y Nutrición, 14004 Córdoba, Spain

Running Title: Kisspeptin signaling in the brain

Corresponding author: Manuel Tena-Sempere

Department of Cell Biology, Physiology and Immunology

Faculty of Medicine, University of Córdoba

Avda. Menéndez Pidal s/n

14004 Córdoba, SPAIN

FAX: +34-957-218288; E-mail: fi1tesem@uco.es

Abbreviation Footnote: GPR54, G protein-coupled receptor 54; GnRH, gonadotropin releasing hormone; $\mathrm{LH}$, luteinizing hormone; FSH, follicle-stimulating hormone; ARC, arcuate nucleus; AVPV, anteroventral periventricular nucleus.

Disclosure Statement: The author has nothing to disclose. 


\section{Abstract}

Kisspeptins, a family of peptides encoded by the KISS1 gene which binds GPR54 (or KISS1 receptor), have recently emerged as essential neuropeptide regulators of key aspects of reproductive maturation and function, including puberty onset, neuroendocrine control of ovulation and metabolic regulation of fertility. Yet, while the neuroanatomy of kisspeptin system has begun to be deciphered, and the involvement of kisspeptins in the above phenomena has been experimentally documented in recent years, precise information on the signaling events underlying these functions has remained scarce. Similarly, the nature and mechanisms of action of most of the regulatory signals of KISS1 expression in the brain are largely unknown. In this review, we will comprehensively summarize some of the recent developments in these areas of kisspeptin physiology, with the ultimate aim to delineate unresolved questions and future pathways for the progression of this active field of Neuroendocrinology.

Key Words: Kisspeptin, GPR54, KISS1, GnRH, puberty, ovulation 


\section{Introduction}

Kisspeptins are a family of structurally-related peptides, encoded by the KISS1 gene, with ability to bind and activate the G protein-coupled receptor, GPR54; recently renamed KISS1 receptor (KISS1R) [1-3]. The first biological actions attributed to kisspeptins were related to their capacity to inhibit tumor metastasis in several malignancies [1]. In fact, the major kisspeptin product was originally named metastin due to its actions as metastasis suppressor in melanoma cells [4]; yet, the actual role of kisspeptins in restraining tumor spread remains contentious. A major twist in this field, however, took place in late 2003, when humans and mice with genetic inactivation of GPR54/KISS1R were found to suffer hypogonadotropic hypogonadism $[5,6]$. From that moment onwards, an ever growing number of research groups worldwide have pursuit the characterization of the physiological roles and mechanisms of action of kisspeptins in the control of reproduction; an intensive work that has resulted, in less than 5 years, in more than 150 original research articles, which have substantiated the crucial functions of this family of molecules in key aspects of reproductive maturation and function.

Considering the astonishing progress of understanding of the physiology of this system accomplished recently, an integral compilation of all the well-known facets of kisspeptins as indispensable players in the reproductive brain clearly exceeds the scope of this review, and can be found elsewhere. On the contrary, this work intends to identify hot areas of kisspeptin physiology, aiming to provide a last-minute view of recent progress and predictable pathways for future research in these particular lines. For sake of uniformity, we will adopt herein the recent proposal for nomenclature by Gottsch and colleagues [7], where KISS1 and Kiss1 are used to name the human and non-human genes, whereas GPR54 is termed KISS1R or Kiss1R, depending on the species. For global reference to the system (i.e., not for a given species), the term KISS1 will be used. Finally, as consensus nomenclature, the peptide products of KISS1 will be globally termed kisspeptins (Kp), with a numeric extension to indicate the amino acid length, when considered relevant.

\section{Kisspeptin Signaling: Molecular Biology of KISS1R}

Identification of KISS1R as the cognate receptor for kisspeptin dates back to 2001, when three independent groups de-orphanized the former GPR54 and initially addressed the molecular analysis of its major signaling pathways $[4,8,9]$. Curiously enough, upon disclosure of the 'reproductive' dimension of kisspeptins, largely based on the characterization of the reproductive phenotypes of humans and mice with null mutations of their receptor, efforts devoted to unravel key aspects of brain kisspeptin distribution and biological actions have been disproportionately larger than those focused on KISS1R. For instance, while mapping of kisspeptin neurons has been conducted in several species, from fish to rodents and humans $[1,10]$, data on the major sites of expression of KISS1R in 
hypothalamic and other brain areas are still scarce. Similarly, while the ability of kisspeptins to potently elicit GnRH and gonadotropin secretion has been conclusively documented in mammals and non-mammalian species [1,11], our knowledge on the molecular mechanisms for KISS1R signaling, from receptor activation to signal transduction and desensitization, remains largely incomplete. Considering the obvious therapeutic potential of kisspeptins for pharmacological manipulation of the gonadotropic axis, it is predictable that this area will draw considerable attention in the near future.

Given that kisspeptins act primarily on $\mathrm{GnRH}$ neurons to activate the gonadotropic axis, analysis of the intracellular signaling pathways responsible for such stimulatory effects has been conducted using hypothalamic explants and protocols of pharmacological blockade of key intracellular signals/factors following ex vivo stimulation with kisspeptin [12]. This approach evidenced that the stimulatory effects of $\mathrm{Kp}-10$ on $\mathrm{GnRH}$ secretion require the activation of phospholipase-C (PLC), mobilization of intracellular $\mathrm{Ca}^{2+}$ stores and recruitment of ERK1/2 and p38 kinases, while kisspeptininduced GnRH release was preserved in spite of the blockade of adenylate cyclase (Figure 1); features that are grossly similar to those initially reported for KISS1R signaling using heterologous cell systems [9]. Likewise, recent studies involving electrophysiological recordings and/or calcium imaging in GnRH neurons have supported and extended those observations, showing that long-term excitation of $\mathrm{GnRH}$ neurons by kisspeptin is conveyed through a PLC/calcium dependent pathway regulating multiple ion channels, including the closing of potassium channels and the activation of non-selective cation (NSC) channels, which likely include canonical transient receptor potential (TRPC) channels [13-15].

In contrast to the above progress in terms of receptor signalling, dissection of the functional anatomy of KISS1R is still at its infancy, but it will be certainly assisted by analyses of the phenotypic and biochemical consequences of known mutations of this receptor in humans (see Figure 2). Although globally rare, these have been enormously instrumental to identify crucial areas for receptor activation and signal transduction [3]. For instance, molecular analysis of the diseasecausing mutation L148S at the second intracellular loop of KISS1R has allowed to reveal the importance of this domain for ligand-induced catalytic activation of $\mathrm{G} \alpha$ subunits, but not for receptor expression or ligand binding [16]. Predictably, analyses on other inactivating mutations of KISS1R will help to identify residues critical for different aspects of receptor function. On the other hand, the first activating mutation of KISS1R (R386P) has been recently reported as cause for precocious puberty [17]. Interestingly, this amino acid substitution does not affect receptor signaling machinery itself, but apparently prolongs receptor activation upon ligand binding, probably due to a reduction in the rate of desensitization of the mutant [17]. This observation underscores a key domain for KISS1R desensitization; a phenomenon whose mechanisms (e.g., internal phosphorylation and/or arresting 
binding) remain unexplored. Finally, as additional source of signaling complexity, molecular analyses in HEK293 cells have recently suggested the potential hetero-oligomerization of KISS1R and GnRH receptors [18]; yet, the relevance of this putative interaction in physiological conditions (i.e., in real GnRH neurons) is completely unknown.

\section{Control of GnRH neurons by kisspeptin pathways}

As essential afferents controlling GnRH neurons, extensive efforts have been recently devoted to identify the location of neurons expressing KISS1/kisspeptins in the basal forebrain of a large diversity of species, from non-mammals (e.g., fish) to rodents and humans. Despite some minor discrepancies between RNA and protein data, mapping of kisspeptin neurons in rodents has conclusively documented the existence of two major neuronal populations located at the arcuate (ARC) and anteroventral periventricular (AVPV) nuclei of the hypothalamus [19]; the latter extending probably as a continuum along the rostral periventricular area of the third ventricle (RV3P) [20]. Besides important functional divergences in sex steroid regulation (see Section 4), these two populations appear to display important anatomical differences in terms of projections to $\mathrm{GnRH}$ neurons, as direct appositions have been reported only from the AVPV [21]. Pending of further refinement of tracing analyses, it is highly plausible, although yet to be proven, that kisspeptin neurons from ARC interact with elements of the pre-synaptic network controlling GnRH neurons (if not GnRH neurons themselves). Indeed, both direct and trans-synaptic (indirect) actions of kisspeptins on GnRH neurons have been documented in female mice [22]. Of important note, while AVPV neurons have been involved in the generation of the pre-ovulatory surge of gonadotropins in the female by mediating positive feedback effects of estradiol, kisspeptin neurons at the ARC have been proposed to convey the negative feedback effects of sex steroids [1] (Figure 3). The molecular basis for such disparate functions is yet to be defined (see Section 4).

In contrast to rodents, in sheep and primates, hypothalamic neurons expressing KISS1/kisspeptin appear to be concentrated mostly at the ARC/infundibular region. Interestingly, in the sheep, kisspeptin neurons mediating positive and negative feedback effects of sex steroids seem to be intermingled within the ARC; neurons responding positively to estrogen being mostly located at its caudal portion [23]. In primates, including humans, only inhibitory responses to sex steroids have been documented in ARC/infundibular neurons, as major mechanism for their negative feedback on gonadotropin secretion [24-26] (see Section 4). It remains to be defined whether and how kisspeptin neurons contribute to the generation of the pre-ovulatory surges in primates.

In addition to neuroanatomical evidence for physical contacts between kisspeptin and GnRH neurons, initial expression analyses demonstrated that $>85 \%$ of GnRH neurons in the rat forebrain express Kiss1R [27], thus providing the basis for direct excitatory effects of kisspeptins. This 
contention was reinforced by the observation of long-lasting depolarizing responses in GnRH neurons following exposure to Kp-10 [28]. Intriguingly, however, despite robust GnRH neuron activation and secretion induced by kisspeptins in different species, electrophysiological studies have recently revealed the existence of two distinct populations of $\mathrm{GnRH}$ neurons at least in rodents; one being (surprisingly) insensitive to kisspeptin but highly responsive to group I metabotropic glutamate receptor agonists [15]. The physiological relevance of such a subset of GnRH neurons irresponsive to kisspeptin awaits to be further elucidated.

\section{Major regulators of KISS1 expression: Central and peripheral factors}

As complement to neuroanatomical analyses, increasing efforts have been devoted to understand the mechanisms and signals whereby hypothalamic expression of KISS1/kisspeptins is regulated, as a mean to unravel their major physiological functions within the reproductive brain. As clear example, initial studies on this system were focused in the analysis of the regulatory roles of sex steroids [1]. As indicated above, compelling evidence gathered mostly in rodents, sheep and primates has demonstrated that KISS1 expression is under the control of estrogens and androgens, with divergent effects depending on the hypothalamic site. Thus, it is well documented that expression of Kiss1/kisspeptins in ARC neurons in tonically repressed by sex steroids in rodents $[29,30]$. Likewise, Kiss1 mRNA levels were found to be inhibited by androgen, estrogen and progesterone in sheep and/or monkeys [24,31]. Indirect proof for the presence of a similar mechanism in humans comes form expression analyses in postmenopausal women that showed increased KISS1 mRNA expression at the infundibular region of the hypothalamus [25]. Intriguingly, sex steroid regulation of Kiss1 mRNA expression at the AVPV region, at least in rodents, seems to be diametrically opposite, with androgens and estrogens carrying stimulatory actions $[29,30]$. The molecular basis for such a disparate regulation of gene expression by similar signals in these discrete neuronal populations remains unclear. Thus, promoter analyses have revealed that through Sp1 sites estradiol up-regulates KISS1 promoter expression via estrogen receptor (ER) $\alpha$; a mechanism that may contribute to its reported effects at the AVPV [32]. However, the inhibitory mode of action of sex steroids at the ARC cannot be explained by this set of data and remains to be elucidated.

While the nature of some of the peripheral regulators of KISS1, such as sex steroids and leptin (see Section 5), has been unraveled in recent years, our knowledge on the major central regulators of hypothalamic kisspeptin neurons is much more limited. These may include, among others, melatonin, neuropeptide $Y$ and IGF-1 [33-35], although their roles in the physiologic control of the KISS1 system in different conditions (from changes in photoperiod to metabolic stress) have not been conclusively defined and merit further investigation. Intriguingly, recent work in sheep has revealed that Kiss1 neurons at the ARC co-express dynorphin (Dyn) and neurokinin-B (NKB) [36], which might operate as 
auto-regulatory signals for kisspeptin neurons in the mouse also. The importance of such coexpression has been recently reinforced by the observation that humans with genetic inactivation of TAC3 or TACR3 genes (which encode for NKB or its putative receptor) suffer from hypogonadotropic hypogonadism [37]. The neuroendocrine basis for such phenomenon, however, is still unclear, as NKB had been reported as inhibitory factor in the control of gonadotropin secretion in different species.

Finally, recent studies in ewes suggested a reciprocal interplay between kisspeptins and the mammalian homologue of gonadotropin-inhibitory hormone $(\mathrm{GnIH})$, termed RFRP, in the central control of GnRH neurons; Kiss1/kisspeptin levels at the ARC being elevated, but RFRP levels at the dorsomedial hypothalamus decreased, at states of maximal activation of the gonadotropic axis (i.e., during the breeding season) [38]. Notably, both kisspeptins and RFRP belong to the super-family of RFamide neuropeptides and, based on their opposite roles in terms of control of gonadotropin secretion, the appealing hypothesis that they are responsible for dynamically driving reproductive function, as a result of the balance between stimulatory (kisspeptin) and inhibitory (RFRP) influences, has been proposed [39]. Yet, the relative potency of these factors, and even their major sites of action within the reproductive axis, seem to be quite different and likely depends on the species; e.g., GnIH appears to play a crucial role in reproductive control in birds, but the Kiss1 gene has not been so far identified in the avian genome [11]. In this scenario, it will be crucial to define whether, in mammals, kisspeptins and RFRP neurons reciprocally regulate each other.

\section{Molecular mechanisms for the metabolic regulation of hypothalamic KISS1}

In recent years, the metabolic regulation of the hypothalamic KISS1 system has been exposed, mainly by experimental studies in rodents, where conditions of negative energy balance were shown to induce variable degrees of inhibition of Kiss1 mRNA expression [34,40-43]. These analyses, together with the rescue of gonadotropic function by exogenous kisspeptin in these conditions, have allowed us to suggest that kisspeptin neurons at the hypothalamus operate as sensor and neuroendocrine conduit for conveying metabolic information onto brain reproductive centers (likely, $\mathrm{GnRH}$ neurons), thereby contributing to the well-known coupling between body energy status, puberty onset and fertility $[42,44]$.

The regulatory network responsible for the metabolic control of the KISS1 system is far from being fully elucidated. Compelling evidence, though, has demonstrated that the adipose hormone, leptin, is a master hormonal regulator of hypothalamic Kiss1, as evidenced by rodent studies, where conditions of hypoleptinemia were linked to decreased hypothalamic expression of Kiss1 mRNA, which could be rescued by central administration of leptin [41,45]. However, some crucial facets of this regulatory pathway remain to be unfolded. For instance, whether leptin operates in physiologic conditions as elicitor or permissive factor for kisspeptin expression and/or release remains to be 
defined; the latter would fit well with the proposed role of leptin as permissive (but not trigger) for puberty onset, but would necessarily require the concurrent action of additional regulators of kisspeptin neurons, whose nature is yet to be characterized.

Likewise, the molecular mechanisms whereby leptin activates Kiss1 gene expression remain largely unknown. Admittedly, however, our knowledge on this area has recently enlarged by the demonstration of the putative role of the Creb1 coactivator, Crtc1, as positive transcriptional regulator of Kiss1 gene expression at discrete hypothalamic areas [46]. Importantly, genetic inactivation of Crtc1 in mice results in infertility and decreased levels of expression of Kiss1 mRNA, whereas leptin increased recruitment of Crct1 onto the Kiss1 promoter [46]. These data suggest the existence of a leptin-Crtc1-kisspeptin signaling pathway, as indispensable for normal reproductive function. In the same vein, we have recently obtained evidence that brain signaling through sensors of the intracellular energy state, such as the mammalian target of rapamycin (MTOR) and AMP kinase (AMPK), is likely to play a crucial role in the central control of puberty onset, eventually via modulation of Kiss1 gene expression at the hypothalamus, as we have preliminarily observed at least for mTOR signaling (unpublished data). Of note, both MTOR and AMPK have been proposed as transducer of leptin effects in terms of energy homeostasis [47]. Altogether, these observations disclose an additional level of complexity in the metabolic regulation of hypothalamic KISS1 system, whereby a set of intracellular sensors and transcriptional factors are likely to cooperate in order to mediate the effects of extracellular signals (e.g., leptin) on the expression of KISS1 gene.

\section{Open questions and future directions}

As summarized in previous sections, our understanding of the roles and modes of action of kisspeptins as indispensable regulators of the reproductive brain has dramatically expanded in the last five years. Of note, identification of the crucial functions of kisspeptin neurons in discrete hypothalamic areas has not only allowed to propose discernible neural pathways for key regulatory phenomena of the reproductive axis, such as positive and negative feedback as well as metabolic control of fertility, but has also forced the scientific community to reassess the functional roles and mechanisms of action of many classical neurotransmitters and neuropeptides, already known to modulate GnRH function, within this novel conceptual framework.

Anyhow, despite the enormous advancements in the field, several key aspects of kisspeptin physiology remain to be fully elucidated and will certainly concentrate considerable attention in the near future. These will likely include (i) better characterization of the functional anatomy, biochemical function and neuronal distribution of KISS1R in different mammalian species, including humans; (ii) mapping of the afferents to and projections of kisspeptin neurons in the brain, and particularly within the hypothalamus, in relation to the pre-synaptic networks controlling $\mathrm{GnRH}$ 
secretion; (iii) identification of additional central and peripheral regulators of hypothalamic KISS1 expression, as well as their roles in the physiologic control of the KISS1 system; (iv) unraveling of the molecular mechanisms for sex steroid (i.e., disparate effects of estrogen at ARC and AVPV) and metabolic control of KISS1 expression; and (v) definition of the actual roles of kisspeptins (trigger vs. amplifier) in the control of puberty onset and the $\mathrm{GnRH}$ pulse generator. In parallel, (vi) it is anticipated that further progress will be made towards the characterization of kisspeptins as targets for pharmacological intervention of the reproductive system, as well as the identification/ generation of analogs of kisspeptins, with either agonist or antagonist activities at the KISS1R level. Overall, it is foreseen that such research efforts will result in a substantial progress of our understanding of the physiological basis, and eventual physiopathological implications, of kisspeptin signaling in the brain, and how it contributes to the dynamic regulation (and potential alteration) of reproductive maturation and function along the life-span.

\section{Acknowledgments}

The author is indebted with the members of the research team at the Physiology Section of the University of Cordoba, who actively participated in the generation of experimental data discussed herein. The assistance of J. Roa in the preparation of some of the figures of this paper is cordially appreciated. The work from the author's laboratory reviewed in this article was supported by grants BFU 2005-07446 and BFU 2008-00984 (Ministerio de Ciencia e Innovación, Spain), funds from Instituto de Salud Carlos III (Red de Centros RCMN C03/08 and Project PI042082; Ministerio de Sanidad, Spain), and EU research contracts EDEN QLK4-CT-2002-00603 and DEER FP7-ENV-2007-1. CIBER is an initiative of Instituto de Salud Carlos III (Ministerio de Sanidad, Spain). 


\section{References}

[1] Roa, J., Aguilar, E., Dieguez, C., Pinilla, L. and Tena-Sempere, M. (2008) New frontiers in kisspeptin/GPR54 physiology as fundamental gatekeepers of reproductive function. Front Neuroendocrinol 29, 48-69.

[2] Popa, S.M., Clifton, D.K. and Steiner, R.A. (2008) The Role of Kisspeptins and GPR54 in the Neuroendocrine Regulation of Reproduction. Annu Rev Physiol 70, 213-238.

[3] Roseweir, A.K. and Millar, R.P. (2009) The role of kisspeptin in the control of gonadotrophin secretion. Hum Reprod Update 15, 203-12.

[4] Ohtaki, T., Shintani, Y., Honda, S., Matsumoto, H., Hori, A., Kanehashi, K., Terao, Y., Kumano, S., Takatsu, Y., Masuda, Y., Ishibashi, Y., Watanabe, T., Asada, M., Yamada, T., Suenaga, M., Kitada, C., Usuki, S., Kurokawa, T., Onda, H., Nishimura, O. and Fujino, M. (2001) Metastasis suppressor gene KiSS-1 encodes peptide ligand of a G-protein-coupled receptor. Nature 411, 613-7.

[5] de Roux, N., Genin, E., Carel, J.C., Matsuda, F., Chaussain, J.L. and Milgrom, E. (2003) Hypogonadotropic hypogonadism due to loss of function of the KiSS1-derived peptide receptor GPR54. Proc Natl Acad Sci U S A 100, 10972-6.

[6] Seminara, S.B., Messager, S., Chatzidaki, E.E., Thresher, R.R., Acierno, J.S., Jr., Shagoury, J.K., Bo-Abbas, Y., Kuohung, W., Schwinof, K.M., Hendrick, A.G., Zahn, D., Dixon, J., Kaiser, U.B., Slaugenhaupt, S.A., Gusella, J.F., O'Rahilly, S., Carlton, M.B., Crowley, W.F., Jr., Aparicio, S.A. and Colledge, W.H. (2003) The GPR54 gene as a regulator of puberty. N Engl J Med 349, 1614-27.

[7] Gottsch, M.L., Clifton, D.K. and Steiner, R.A. (2009) From KISS1 to kisspeptins: An historical perspective and suggested nomenclature. Peptides 30, 4-9.

[8] Muir, A.I., Chamberlain, L., Elshourbagy, N.A., Michalovich, D., Moore, D.J., Calamari, A., Szekeres, P.G., Sarau, H.M., Chambers, J.K., Murdock, P., Steplewski, K., Shabon, U., Miller, J.E., Middleton, S.E., Darker, J.G., Larminie, C.G., Wilson, S., Bergsma, D.J., Emson, P., Faull, R., Philpott, K.L. and Harrison, D.C. (2001) AXOR12, a novel human G protein-coupled receptor, activated by the peptide KiSS-1. J Biol Chem 276, 28969-75.

[9] Kotani, M., Detheux, M., Vandenbogaerde, A., Communi, D., Vanderwinden, J.M., Le Poul, E., Brezillon, S., Tyldesley, R., Suarez-Huerta, N., Vandeput, F., Blanpain, C., Schiffmann, S.N., Vassart, G. and Parmentier, M. (2001) The metastasis suppressor gene KiSS-1 encodes kisspeptins, the natural ligands of the orphan G protein-coupled receptor GPR54. J Biol Chem 276, 34631-6.

[10] Roa, J. and Tena-Sempere, M. (2007) KiSS-1 system and reproduction: comparative aspects and roles in the control of female gonadotropic axis in mammals. Gen Comp Endocrinol 153, 132-40.

[11] Felip, A., Zanuy, S., Pineda, R., Pinilla, L., Carrillo, M., Tena-Sempere, M. and Gomez, A. (2008) Evidence for two distinct KiSS genes in non-placental vertebrates that encode kisspeptins with different gonadotropin-releasing activities in fish and mammals. Mol Cell Endocrinol.

[12] Castellano, J.M., Navarro, V.M., Fernandez-Fernandez, R., Castano, J.P., Malagon, M.M., Aguilar, E., Dieguez, C., Magni, P., Pinilla, L. and Tena-Sempere, M. (2006) Ontogeny and mechanisms of action for the stimulatory effect of kisspeptin on gonadotropin-releasing hormone system of the rat. Mol Cell Endocrinol 257-258, 75-83.

[13] Liu, X., Lee, K. and Herbison, A.E. (2008) Kisspeptin excites gonadotropin-releasing hormone neurons through a phospholipase $\mathrm{C} /$ calcium-dependent pathway regulating multiple ion channels. Endocrinology 149, 4605-14.

[14] Zhang, C., Roepke, T.A., Kelly, M.J. and Ronnekleiv, O.K. (2008) Kisspeptin depolarizes gonadotropinreleasing hormone neurons through activation of TRPC-like cationic channels. J Neurosci 28, 4423-34.

[15] Dumalska, I., Wu, M., Morozova, E., Liu, R., van den Pol, A. and Alreja, M. (2008) Excitatory effects of the puberty-initiating peptide kisspeptin and group I metabotropic glutamate receptor agonists differentiate two distinct subpopulations of gonadotropin-releasing hormone neurons. J Neurosci 28 , 8003-13.

[16] Wacker, J.L., Feller, D.B., Tang, X.B., Defino, M.C., Namkung, Y., Lyssand, J.S., Mhyre, A.J., Tan, X., Jensen, J.B. and Hague, C. (2008) Disease-causing mutation in GPR54 reveals the importance of the second intracellular loop for class A G-protein-coupled receptor function. J Biol Chem 283, 31068-78. 
[17] Teles, M.G., Bianco, S.D., Brito, V.N., Trarbach, E.B., Kuohung, W., Xu, S., Seminara, S.B., Mendonca, B.B., Kaiser, U.B. and Latronico, A.C. (2008) A GPR54-activating mutation in a patient with central precocious puberty. N Engl J Med 358, 709-15.

[18] Quaynor, S., Hu, L., Leung, P.K., Feng, H., Mores, N., Krsmanovic, L.Z. and Catt, K.J. (2007) Expression of a functional g protein-coupled receptor 54-kisspeptin autoregulatory system in hypothalamic gonadotropin-releasing hormone neurons. Mol Endocrinol 21, 3062-70.

[19] Mikkelsen, J.D. and Simonneaux, V. (2009) The neuroanatomy of the kisspeptin system in the mammalian brain. Peptides 30, 26-33.

[20] Herbison, A.E. (2008) Estrogen positive feedback to gonadotropin-releasing hormone (GnRH) neurons in the rodent: The case for the rostral periventricular area of the third ventricle (RP3V). Brain Res Rev 57, 277-287.

[21] Clarkson, J. and Herbison, A.E. (2006) Postnatal development of kisspeptin neurons in mouse hypothalamus; sexual dimorphism and projections to gonadotropin-releasing hormone neurons. Endocrinology 147, 5817-25.

[22] Pielecka-Fortuna, J., Chu, Z. and Moenter, S.M. (2008) Kisspeptin acts directly and indirectly to increase gonadotropin-releasing hormone neuron activity and its effects are modulated by estradiol. Endocrinology 149, 1979-86.

[23] Estrada, K.M., Clay, C.M., Pompolo, S., Smith, J.T. and Clarke, I.J. (2006) Elevated KiSS-1 expression in the arcuate nucleus prior to the cyclic preovulatory gonadotrophin-releasing hormone/lutenising hormone surge in the ewe suggests a stimulatory role for kisspeptin in oestrogen-positive feedback. J Neuroendocrinol 18, 806-9.

[24] Shibata, M., Friedman, R.L., Ramaswamy, S. and Plant, T.M. (2007) Evidence that down regulation of hypothalamic KiSS-1 expression is involved in the negative feedback action of testosterone to regulate luteinising hormone secretion in the adult male rhesus monkey (Macaca mulatta). J Neuroendocrinol 19, 432-8.

[25] Rometo, A.M., Krajewski, S.J., Voytko, M.L. and Rance, N.E. (2007) Hypertrophy and increased kisspeptin gene expression in the hypothalamic infundibular nucleus of postmenopausal women and ovariectomized monkeys. J Clin Endocrinol Metab 92, 2744-50.

[26] Kim, W., Jessen, H.M., Auger, A.P. and Terasawa, E. (2009) Postmenopausal increase in KiSS-1, GPR54, and luteinizing hormone releasing hormone (LHRH-1) mRNA in the basal hypothalamus of female rhesus monkeys. Peptides 30, 103-10.

[27] Irwig, M.S., Fraley, G.S., Smith, J.T., Acohido, B.V., Popa, S.M., Cunningham, M.J., Gottsch, M.L., Clifton, D.K. and Steiner, R.A. (2004) Kisspeptin activation of gonadotropin releasing hormone neurons and regulation of KiSS-1 mRNA in the male rat. Neuroendocrinology 80, 264-72.

[28] Han, S.K., Gottsch, M.L., Lee, K.J., Popa, S.M., Smith, J.T., Jakawich, S.K., Clifton, D.K., Steiner, R.A. and Herbison, A.E. (2005) Activation of gonadotropin-releasing hormone neurons by kisspeptin as a neuroendocrine switch for the onset of puberty. J Neurosci 25, 11349-56.

[29] Smith, J.T., Dungan, H.M., Stoll, E.A., Gottsch, M.L., Braun, R.E., Eacker, S.M., Clifton, D.K. and Steiner, R.A. (2005) Differential regulation of KiSS-1 mRNA expression by sex steroids in the brain of the male mouse. Endocrinology 146, 2976-84.

[30] Smith, J.T., Cunningham, M.J., Rissman, E.F., Clifton, D.K. and Steiner, R.A. (2005) Regulation of Kiss1 gene expression in the brain of the female mouse. Endocrinology 146, 3686-92.

[31] Smith, J.T., Clay, C.M., Caraty, A. and Clarke, I.J. (2007) KiSS-1 messenger ribonucleic acid expression in the hypothalamus of the ewe is regulated by sex steroids and season. Endocrinology 148, 1150-7.

[32] Li, D., Mitchell, D., Luo, J., Yi, Z., Cho, S.G., Guo, J., Li, X., Ning, G., Wu, X. and Liu, M. (2007) Estrogen Regulates KiSS1 Gene Expression through Estrogen Receptor \{alpha\} and SP Protein Complexes. Endocrinology 148, 4821-8.

[33] Revel, F.G., Saboureau, M., Masson-Pevet, M., Pevet, P., Mikkelsen, J.D. and Simonneaux, V. (2006) Kisspeptin mediates the photoperiodic control of reproduction in hamsters. Curr Biol 16, 1730-5.

[34] Luque, R.M., Kineman, R.D. and Tena-Sempere, M. (2007) Regulation of Hypothalamic Expression of KiSS-1 and GPR54 Genes by Metabolic Factors: Analyses Using Mouse Models and a Cell Line. Endocrinology 148, 4601-11. 
[35] Hiney, J.K., Srivastava, V.K., Pine, M.D. and Les Dees, W. (2009) Insulin-like growth factor-I activates KiSS-1 gene expression in the brain of the prepubertal female rat. Endocrinology 150, 376-84.

[36] Goodman, R.L., Lehman, M.N., Smith, J.T., Coolen, L.M., de Oliveira, C.V., Jafarzadehshirazi, M.R., Pereira, A., Iqbal, J., Caraty, A., Ciofi, P. and Clarke, I.J. (2007) Kisspeptin neurons in the arcuate nucleus of the ewe express both dynorphin A and neurokinin B. Endocrinology 148, 5752-60.

[37] Topaloglu, A.K., Reimann, F., Guclu, M., Yalin, A.S., Kotan, L.D., Porter, K.M., Serin, A., Mungan, N.O., Cook, J.R., Ozbek, M.N., Imamoglu, S., Akalin, N.S., Yuksel, B., O'Rahilly, S. and Semple, R.K. (2008) TAC3 and TACR3 mutations in familial hypogonadotropic hypogonadism reveal a key role for Neurokinin B in the central control of reproduction. Nat Genet.

[38] Smith, J.T., Coolen, L.M., Kriegsfeld, L.J., Sari, I.P., Jaafarzadehshirazi, M.R., Maltby, M., Bateman, K., Goodman, R.L., Tilbrook, A.J., Ubuka, T., Bentley, G.E., Clarke, I.J. and Lehman, M.N. (2008) Variation in kisspeptin and RFamide-related peptide (RFRP) expression and terminal connections to gonadotropinreleasing hormone neurons in the brain: a novel medium for seasonal breeding in the sheep. Endocrinology 149, 5770-82.

[39] Kriegsfeld, L.J. (2006) Driving reproduction: RFamide peptides behind the wheel. Horm Behav 50, 65566.

[40] Castellano, J.M., Navarro, V.M., Fernandez-Fernandez, R., Nogueiras, R., Tovar, S., Roa, J., Vazquez, M.J., Vigo, E., Casanueva, F.F., Aguilar, E., Pinilla, L., Dieguez, C. and Tena-Sempere, M. (2005) Changes in hypothalamic KiSS-1 system and restoration of pubertal activation of the reproductive axis by kisspeptin in undernutrition. Endocrinology 146, 3917-25.

[41] Castellano, J.M., Navarro, V.M., Fernandez-Fernandez, R., Roa, J., Vigo, E., Pineda, R., Dieguez, C., Aguilar, E., Pinilla, L. and Tena-Sempere, M. (2006) Expression of hypothalamic KiSS-1 system and rescue of defective gonadotropic responses by kisspeptin in streptozotocin-induced diabetic male rats. Diabetes 55, 2602-10.

[42] Castellano, J.M., Roa, J., Luque, R.M., Dieguez, C., Aguilar, E., Pinilla, L. and Tena-Sempere, M. (2009) KiSS-1/kisspeptins and the metabolic control of reproduction: Physiologic roles and putative physiopathological implications. Peptides 30, 139-145.

[43] Castellano, J.M., Navarro, V.M., Roa, J., Pineda, R., Sanchez-Garrido, M.A., Garcia-Galiano, D., Vigo, E., Dieguez, C., Aguilar, E., Pinilla, L. and Tena-Sempere, M. (2009) Alterations in Hypothalamic KiSS-1 System in Experimental Diabetes: Early Changes and Functional Consequences. Endocrinology 150, 784-794.

[44] Tena-Sempere, M. (2006) KiSS-1 and reproduction: focus on its role in the metabolic regulation of fertility. Neuroendocrinology 83, 275-81.

[45] Smith, J.T., Acohido, B.V., Clifton, D.K. and Steiner, R.A. (2006) KiSS-1 neurones are direct targets for leptin in the ob/ob mouse. J Neuroendocrinol 18, 298-303.

[46] Altarejos, J.Y., Goebel, N., Conkright, M.D., Inoue, H., Xie, J., Arias, C.M., Sawchenko, P.E. and Montminy, M. (2008) The Creb1 coactivator Crtc1 is required for energy balance and fertility. Nat Med 14, 1112-7.

[47] Cota, D., Proulx, K., Smith, K.A., Kozma, S.C., Thomas, G., Woods, S.C. and Seeley, R.J. (2006) Hypothalamic mTOR signaling regulates food intake. Science 312, 927-30.

[48] Roa, J., Castellano, J.M., Navarro, V.M., Handelsman,D.J., Pinilla, L. and Tena-Sempere, M. (2009) Kisspeptins and the control of gonadotropin secretion in male and female rodents. Peptides 30, 57-66. 


\section{Legends to Figures}

Figure 1: Signaling pathways tentatively recruited following activation of KISS1R by kisspeptin (Kp) at the hypothalamus. Based on data from experiments involving stimulation of hypothalamic explants with Kp ex vivo, it is proposed that the GnRH releasing effect of kisspeptin involves the activation of phospholipase-C (PLC), mobilization of intracellular $\mathrm{Ca}^{2+}$ stores and recruitment of ERK1/2 and p38 kinases, but is independent of adenylate cyclase/CAMP pathways. In addition, electrophysiological studies have demonstrated that long-term excitation of $\mathrm{GnRH}$ neurons by Kp is conveyed through modulation of multiple ion channels, including closing of potassium channels (dotted line) and the opening of non-selective cation (NSC) channels, likely of the TRPClike type; for sake of simplicity, only the mechanism involving closing of $K$ channels is depicted in the scheme. For further details, see text. Adapted from ref. [48], with substantial modifications.

Figure 2: Schematic representation of the activating and inactivating mutations of $K I S S 1 R$ gene so far reported. Inactivating mutations are indicated as black dots, with reference to the corresponding amino acid substitution. In addition, the location of the predicted deletion reported in ref. [5] is marked by grey dots. Likewise, the predicted insertion (1001_1002insC), which results in a shift of the open reading frame [3], is denoted by an asterisk. Finally, the first activating mutation of KISS1R, recently found in a patient suffering precocious puberty, is depicted as a grey box. Adapted from ref. [1], with substantial modifications.

Figure 3: Proposed roles of kisspeptin neurons at the arcuate (ARC) and anteroventral periventricular (AVPV) nuclei in mediating the negative and positive feedback effects of ovarian sex steroids on $\mathrm{GnRH}$ and gonadotropin secretion, as suggested on the basis of rodent data. Estrogen (E2) input exerts a predominant inhibitory action on Kiss1 expression at the ARC, which contributes to negative feedback control of $\mathrm{GnRH} / \mathrm{LH}$. In contrast, the rise of E2 levels at the preovulatory period stimulate Kiss1 expression at the AVPV that, in the presence of activated receptors for progesterone $(\mathrm{P})$, contributes to the induction of pre-ovulatory surge of $\mathrm{LH}$ (positive feedback). In addition to transcriptional effects, E2 seems to elicit a state of enhanced responsiveness to kisspeptin, likely at the level of $\mathrm{GnRH}$ neurons, during the peri-ovulatory period (dotted line). For further details, see the text. Adapted from ref. [1], with modifications. 


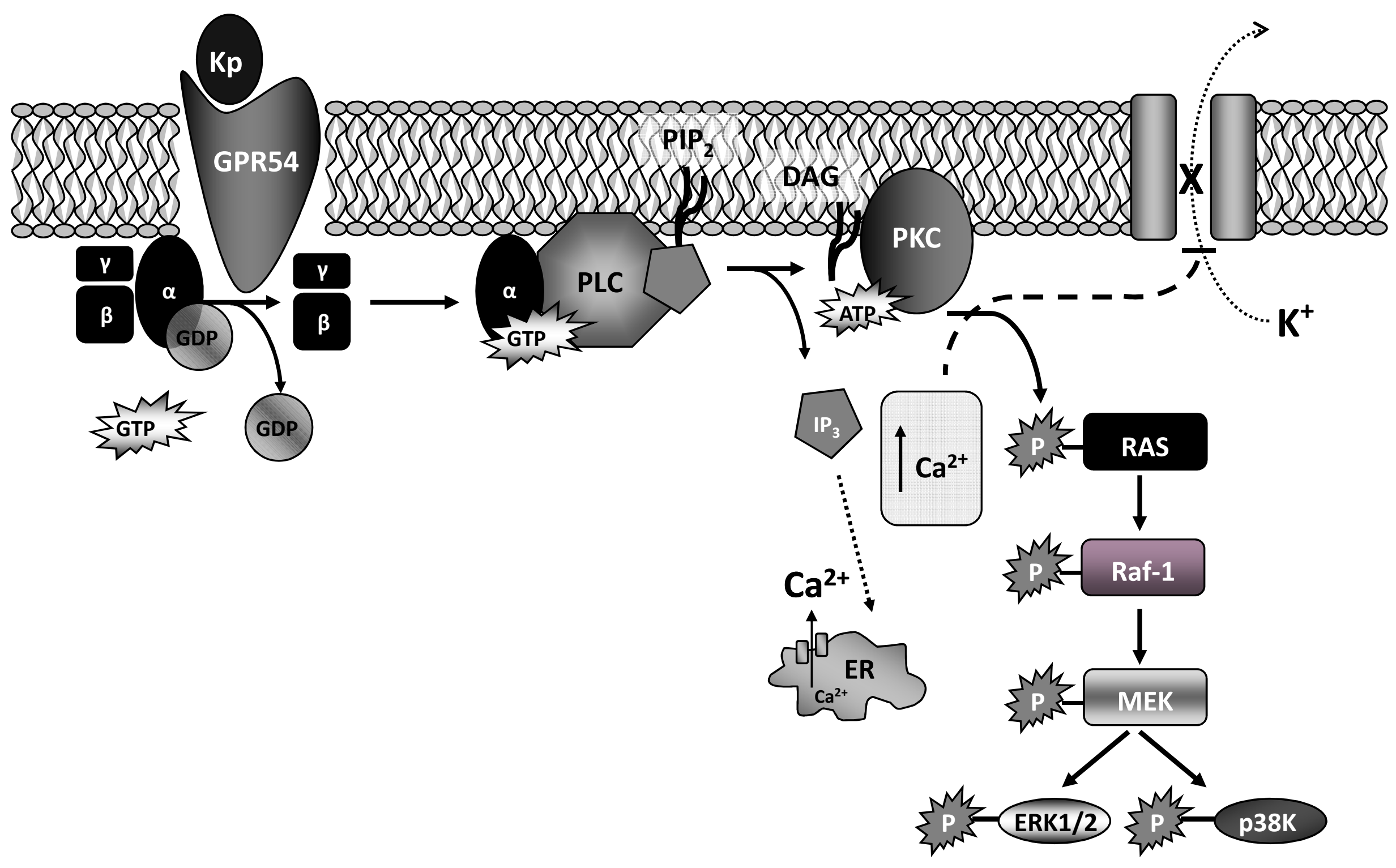

Tena-Sempere

Figure 1 


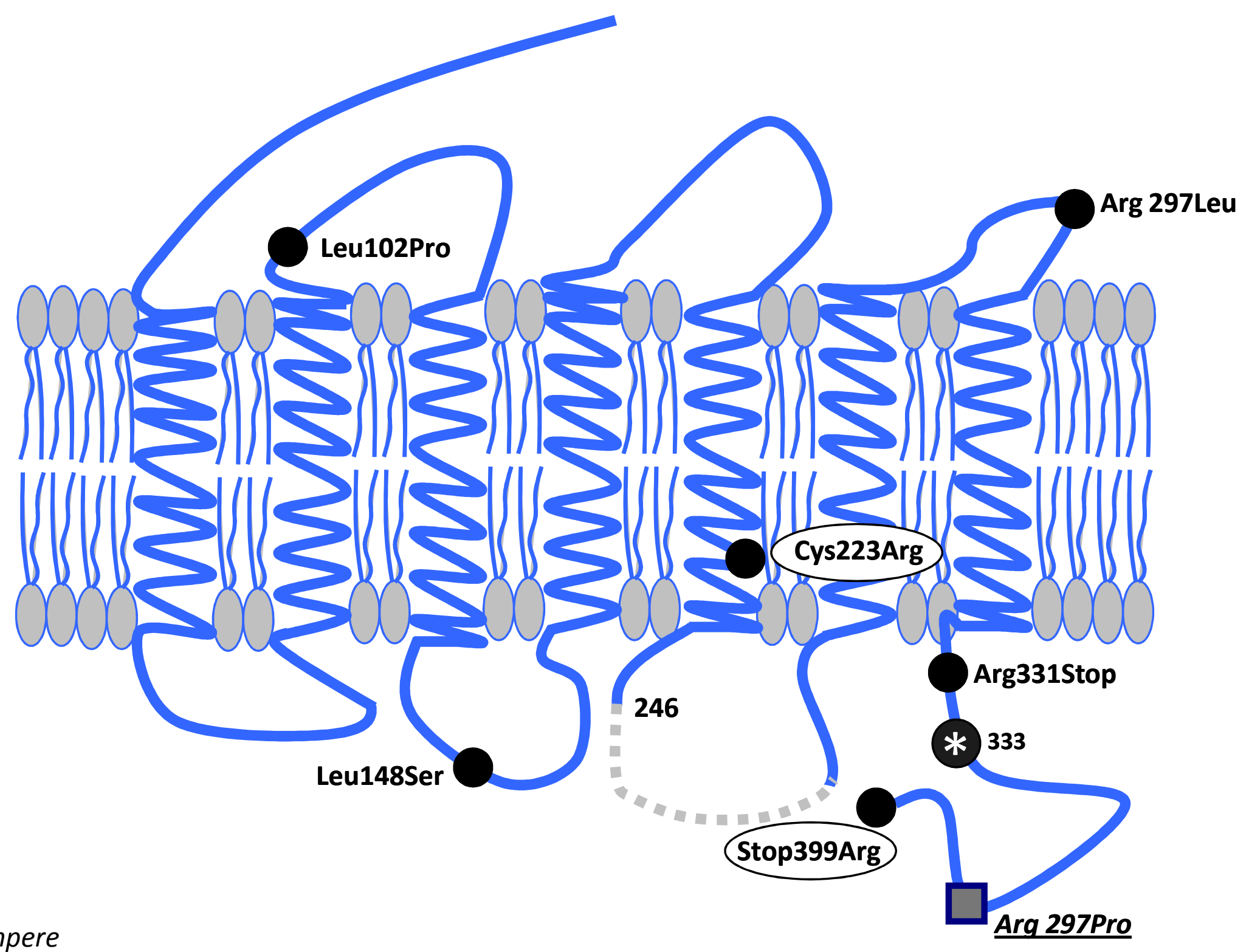

Tena-Sempere

Figure 2 


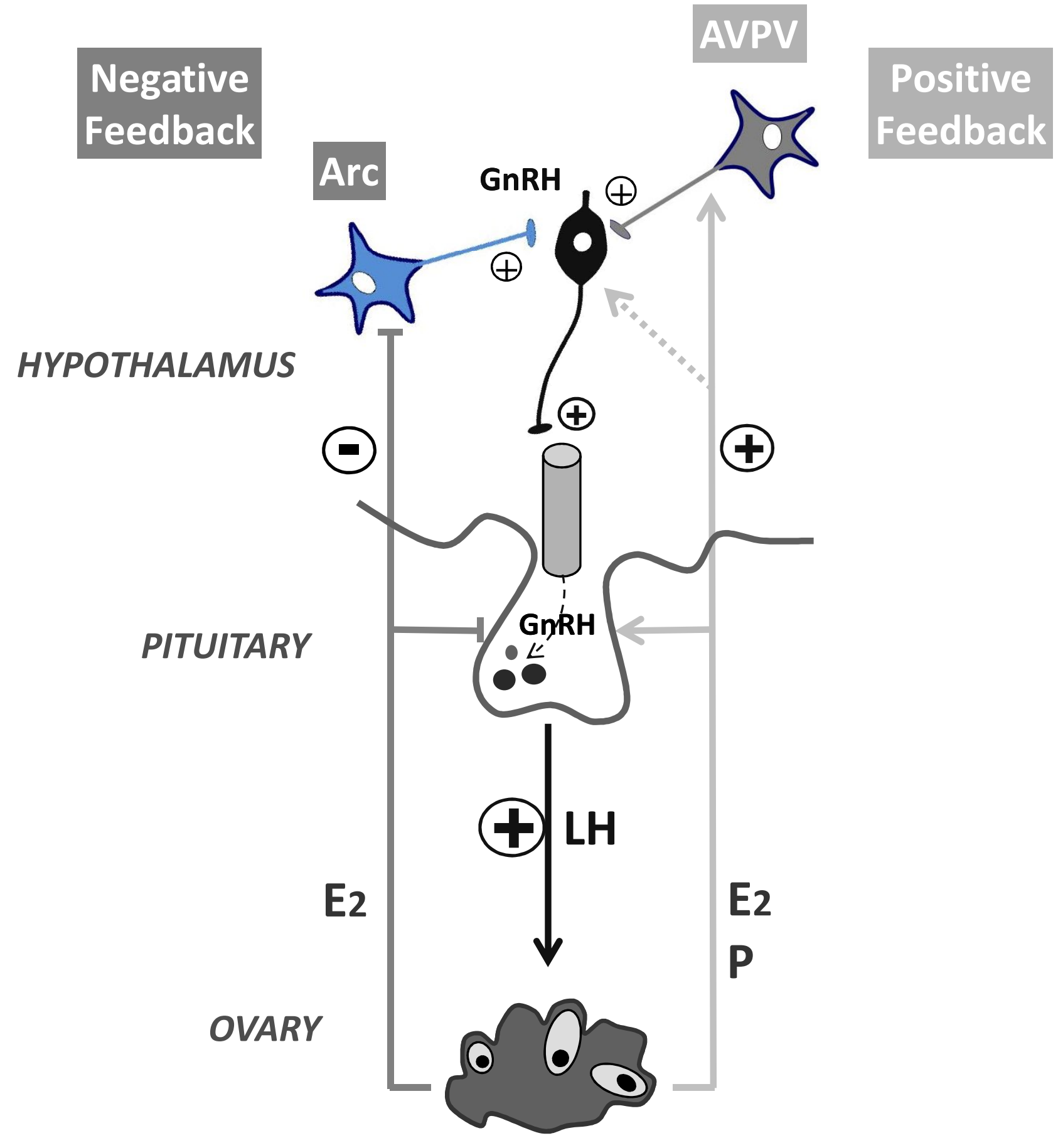

Tena-Sempere

Figure 3 